\title{
Very Early EEG Responses to a Meaningful Auditory Stimulus in the Frontal Lobes: an Intracerebral Study in Humans
}

\author{
M. KUKLETA ${ }^{1}$, B. TURAK ${ }^{2}$, J. LOUVEL $^{2}$ \\ ${ }^{1}$ Department of Physiology, Faculty of Medicine, Masaryk University, Brno, Czech Republic, \\ ${ }^{2}$ INSERM U573 \& Service de Neurochirurgie Stéréotaxique, Hôpital Ste Anne, Paris, France
}

Received June 16, 2009

Accepted March 26, 2010

On-line June 9, 2010

\begin{abstract}
Summary
Frontal auditory evoked potentials (FAEPs) obtained as a response to the warning auditory stimulus of a contingent negative variation task from depth electrodes were investigated. The second, imperative stimulus was visual. Thirteen epileptic patients participated in the study. Records from 20 electrodes of 10 patients exhibited signs of local generation. They were localized in the motor cortices (7 cases), in the superior, medial, and inferior frontal gyri (7 cases), in the cingulate gyrus (5 cases), and in the nucleus caudatus (1 case). A typical FAEP from these generators consisted of three components: (i) first negative wave peaking at $99 \pm 13 \mathrm{~ms}$; (ii) positive wave peaking at $181 \pm 21$ ms; (iii) second negative wave peaking at $324 \pm 63 \mathrm{~ms}$. In 11 generators no evoked activity to visual stimulus was observed; in the remaining 9 generators both auditory and visual stimuli evoked a response. FAEPs with very early onsets (onset latency below $20 \mathrm{~ms}$ ) were found in three sites in the precentral gyrus.
\end{abstract}

\section{Key words}

Intracerebral recording - Human - Frontal auditory evoked potentials • Frontal cortex

\section{Corresponding author}

M. Kukleta, Department of Physiology, Faculty of Medicine, Masaryk University, Komenského 2, 66243 Brno, Czech Republic. E-mail: mkukleta@med.muni.cz

\section{Introduction}

The evidence of the frontal cortex involvement in the generation of auditory evoked potentials (AEP) can be traced back to Walter (1964). In a study dealing with the convergence and interaction of evoked responses in the human frontal cortex, the author reported on responses in the frontal lobes, which were evoked by simple presentation of visual, auditory, and tactile stimuli. In the case of auditory stimuli, single clicks or series of 15 clicks/s delivered repeatedly at randomly varied intervals between 5 and $10 \mathrm{~s}$ were used. Walter, and later also other authors who studied evoked potentials to auditory stimuli recorded outside the auditory cortex, have considered these responses as phenomena linked predominantly with attention (Hari et al. 1982, Perrault and Picton 1984). As the inter-stimulus intervals in these studies were of varying and relatively long duration, the orientation to the novelty in the situation represented by the next stimulus was seen as the major source of these responses. However, Giard et al. (1994) demonstrated the bilateral current sinks over frontal areas, which were evoked by simple auditory stimuli, delivered in $1 \mathrm{~s}$ intervals. This finding could be interpreted as a demonstration of frontal lobe involvement in auditory processing per se.

Later EEG and functional magnetic resonance imaging research demonstrated the involvement of the inferior frontal cortex in the generation of mismatch negativity during auditory change detection (Opitz et al. 2002, Rinne et al. 2005). The finding that the auditory reaction time decreases with increased age until adolescence with a much steeper slope than the central motor conduction time (Fietzek et al. 2000) opened up a new interesting research orientation of frontal lobe involvement in the processing of auditory stimuli. According to Näätänen and Picton (1987), the N1 component of an AEP consists of at least three different 
subcomponents, designated as N1a, N1b, and N1c. The $a$ and $c$ subcomponents exhibit a bilateral temporal maximum on the scalp surface and most likely originate in the lateral auditory association cortices. The $b$ subcomponent peaks around the vertex and involves, besides sources in the temporal auditory cortex, a frontal contribution from the premotor cortices, the supplementary motor area, and the anterior cingulate gyrus (Alcaini et al. 1994, Giard et al. 1994). Recently it was demonstrated that auditory N1 develops with age. The N1a and N1c have been found to decrease in amplitude while N1b becomes larger with increasing age (Goodin et al. 1978, Pang and Taylor 2000, Ponton et al. 2000, Gomes et al. 2001, Ceponiene et al. 2002, Tonnquist-Uhlen et al. 2003). In a study of AEP following the warning stimulus in a contingent negative variation task (CNV), Bender et al. (2006) demonstrated a highly significant continuous increase of the N1b amplitude in adolescents, which was absent in children. A topographical analysis of the average referenced data, current source density and a spatiotemporal source analysis pointed towards a frontal generator of this maturation change.

In a study with subdural electrodes in humans aiming to identify generators of $\mathrm{CNV}$ in the cerebral cortex, Hamano et al. (1997) analyzed auditory evoked potentials elicited by both warning and imperative stimuli of the paradigm. He described the potential with a clear negative peak at about $100 \mathrm{~ms}$ after stimuli, which was recorded by electrodes located close to the Sylvian fissure. The electrodes placed over various frontal, parietal, temporal, and occipital areas recorded several other potentials peaking between 100 and $450 \mathrm{~ms}$. These latter potentials exhibited substantial interindividual and interelectrode variability in the waveform and latency, and were not analyzed in detail in the paper cited.

A basic analysis of evoked potentials recorded intracerebrally from the primary and secondary auditory cortices is presented in a systematic study of LiégeoisChauvel et al. (1994). On the other hand, intracerebral studies of auditory evoked potentials from frontal cortex are rare and sketchy. In several studies in humans using the CNV paradigm, the responses to an auditory stimulus were reported in the frontal cortex but not analyzed in detail (Lamarche et al. 1995, Bareš and Rektor 2001, Turak et al. 2002).

The character of the present study was explorative. We analyzed intracerebrally recorded frontal auditory evoked potentials (FAEPs), which were obtained in a CNV experiment in thirteen epileptic patients during their presurgical diagnostic exploration. In the experiment, a warning auditory stimulus signaled the presentation of an imperative visual stimulus which followed the first one after a $3 \mathrm{~s}$ interval. The interest of the study was focused on data reporting about the generation of FAEPs in an attempt to understand whether these potentials were homogenous in origin or whether their generating signals followed different pathways. The relevant literature did not provide any comparable analysis.

\section{Methods and Materials}

\section{Subjects}

The EEG records of thirteen medically intractable epileptic patients (11 men, 2 women, aged 18 49 years) with depth electrodes implanted to localize the seizure origin were analyzed in the study. All the patients were informed that the experiment had no relevance to their clinical examination, and all agreed to participate. All of them were right-handed. None of them had signs of neurological deficits (hemiparesis or hemiplegia), none of them presented any major overt cognitive deficit. They all were under antiepileptic therapy, which was determined by clinical considerations (sodium valproate, hydantoin, barbiturates, carbamazepine, vigabatrin, benzodiazepines, lamotrigine, clobazam, primidone, gabapentine). During the period of diagnostic examination by intracerebral EEG recording, the doses of medicaments were reduced to allow seizures to develop spontaneously or in response to a focal repetitive electrical stimulation.

\section{Recording procedures}

Depth orthogonal electrodes were implanted according to the clinical and EEG characteristics of the disease. In one patient, additional diagonal electrode was inserted into the amygdalo-hippocampal complex passing through the basal ganglia. Each $0.8 \mathrm{~mm}$ diameter electrode had a series of $2 \mathrm{~mm}$ long stainless steel contacts (maximally 15), with a distance of $1.5 \mathrm{~mm}$ between the contacts. The positions of the contacts were indicated in relation to the axes defined by the Talairach system using the ' $\mathrm{x}, \mathrm{y}, \mathrm{z}$ ' format where ' $\mathrm{x}$ ' is lateral, millimeters to midline, positive right hemisphere, ' $y$ ' is anteroposterior, millimeters to the AC (anterior commissure) line, positive anterior, and ' $\mathrm{z}$ ' is vertical, millimeters to the AC/PC (posterior commissure) line, positive up (Talairach and Szikla 1967). All electrode 
positions were verified radiologically in anteroposterior and lateral views. The experimental session lasted for less than $60 \mathrm{~min}$. During the experiment, patients lay comfortably on a bed and watched a video screen positioned approximately $150 \mathrm{~cm}$ in front of their eyes.

\section{Protocols}

An experimental session was composed of four blocks of trials with 30 trials in each block (the intertrial interval varied randomly from 8 to $12 \mathrm{~s}$ ). In these blocks, the experimental design resembled the protocol used to elicit the $\mathrm{CNV}$ phenomenon - a warning auditory stimulus (S1, pure tone of $400 \mathrm{~Hz}$ frequency and $100 \mathrm{~ms}$ duration delivered through a loudspeaker) was followed, $3 \mathrm{~s}$ later, by a visual stimulus ( $\mathrm{S} 2$, a red cross or circle presented on the dark background of the screen for $100 \mathrm{~ms}$ ) which prompted the patient to execute one of four experimental tasks. In block 1 , the patient was asked to pay simply attention to the visual stimulus (experimental condition 1). In block 2, the patient was instructed to add up silently one of two types of visual patterns specified by the operator. He was asked to give the total number after the last presentation (experimental condition 2). In block 3, the patient was instructed to clench, as rapidly as possible, a joystick after the presentation of S2 stimulus, regardless of whether it was a circle or a cross. The joystick remained in his hand throughout the whole block (experimental condition 3). In block 4, the clenching movement was required at the appearance of a circle, the patient being asked to refrain from moving if presented with a cross (experimental condition 4).

\section{Data acquisition and processing}

The intracerebral EEG activity was recorded on a 32-channel amplifier device (Nihon-Kohden, band pass between 0.016 and $100 \mathrm{~Hz}$ ) fed into a CED 1401+ interface (Cambridge Electronic Design Ltd, UK) with Signal 2 software (CED). Each data frame had a duration of $5 \mathrm{~s}$ and was digitized at a frequency of $200 \mathrm{~Hz}$. The S1 stimulus was triggered by a system interrupt, working with a microsecond precision, exactly $1000 \mathrm{~ms}$ after the start of the recording. All the records were taken with a binaural reference. The data processing was performed off-line using artifact-free EEG records only (the selection was based on visual inspection of records by an experienced person). In all experimental blocks, the analysis window was $5 \mathrm{~s}$. The potential change after $\mathrm{S} 1$ was considered as event-related potential if its amplitude was greater than at least double the maximal potential change seen in the period prior to the stimulus onset. This criterion, which is commonly used in ERP research, was extended by statistical comparison of amplitude values from baseline and ERP. In this case, the criterion of acceptance of the evoked response was the significance of the difference greater than 0.01 . The estimation of onset time of an FAEP took into consideration the ongoing baseline oscillations which preceded it; as a rule, the onset was placed beyond their range. As the records from the neighboring contacts of an electrode were frequently identical, a strict methodical rule was adopted for selection of the data analyzed (one representative record from one electrode in the case of electrodes with a small number of recording contacts, two records from distant contacts in the case of electrodes with a higher number of contacts). A standard procedure was used for the determination of FAEP generator sites: either the finding of polarity reversal between the neighboring records from one electrode or the finding of marked amplitude reduction in a series of records from the neighboring contacts of one electrode. The statistical evaluation of the results was performed by one-way ANOVA and Mann-Whitney $U$ test using the program package Statistica '99 (Statsoft Inc, Tulsa, USA).

\section{Results}

\section{Effect of experimental conditions}

The frontal auditory evoked potentials (FAEPs) were obtained from 292 electrode contacts ( $92 \%$ of all contacts used) of 39 electrodes implanted in the left or right frontal lobes of 13 patients. For each recording contact, the average curves were calculated from records obtained in each experimental condition (one-condition averages) and from grouped records of all conditions (grand or four-condition averages). These two kinds of averages are illustrated in Figure 1. The possible effect of experimental condition on FAEP's shape and location of its components on the time axis was assessed by a comparison of one-condition averages derived from 46 selected contacts (one contact of an electrode in 32 cases, two distant contacts of an electrode in 7 cases). Three parameters could be measured on each of the onecondition average analyzed: the latency of Point $a$, the latency of Point $b$, and the amplitude difference between Points $a$ and $b$ (Fig. 1). Mean values of these parameters and their variability are presented in Table 1.

The statistical analysis of these data by ANOVA demonstrated: 
Table 1. Mean values and variability (standard deviations, minimal and maximal values) of Points $a$ and $b$ latencies and amplitude difference measured on one-condition averages.

\begin{tabular}{|c|c|c|c|c|}
\hline Condition & $\mathbf{N}$ & $\begin{array}{l}\text { Latency } P a \text { in } \mathrm{ms} \\
\text { mean } \pm \text { S.D. } \\
\text { (min - max values) }\end{array}$ & $\begin{array}{l}\text { Latency } P \boldsymbol{b} \text { in } \mathrm{ms} \\
\text { mean } \pm \text { S.D. } \\
(\text { min - max values) }\end{array}$ & $\begin{array}{l}\text { Amplitude } P a-P b \text { in } \mu V \\
\text { mean } \pm \text { S.D. } \\
\text { (min - max values) }\end{array}$ \\
\hline 1 & 46 & $\begin{array}{l}105.4 \pm 22.8 \\
(50-153)\end{array}$ & $\begin{array}{l}182.7 \pm 31.4 \\
(130-284)\end{array}$ & $\begin{array}{l}47.0 \pm 17.2 \\
(26-97)\end{array}$ \\
\hline 2 & 46 & $\begin{array}{l}105.0 \pm 21.3 \\
(61-178)\end{array}$ & $\begin{array}{l}184.0 \pm 32.8 \\
(130-307)\end{array}$ & $\begin{array}{l}41.3 \pm 16.6 \\
(20-98)\end{array}$ \\
\hline 3 & 46 & $\begin{array}{l}104.8 \pm 16.3 \\
(66-140)\end{array}$ & $\begin{array}{l}177.8 \pm 32.7 \\
(132-294)\end{array}$ & $\begin{array}{l}42.4 \pm 21.6 \\
(12-107)\end{array}$ \\
\hline 4 & 46 & $\begin{array}{l}107.1 \pm 18.0 \\
(66-151)\end{array}$ & $\begin{array}{l}181.6 \pm 33.1 \\
(126-307)\end{array}$ & $\begin{array}{l}38.9 \pm 17.0 \\
(10-98)\end{array}$ \\
\hline
\end{tabular}

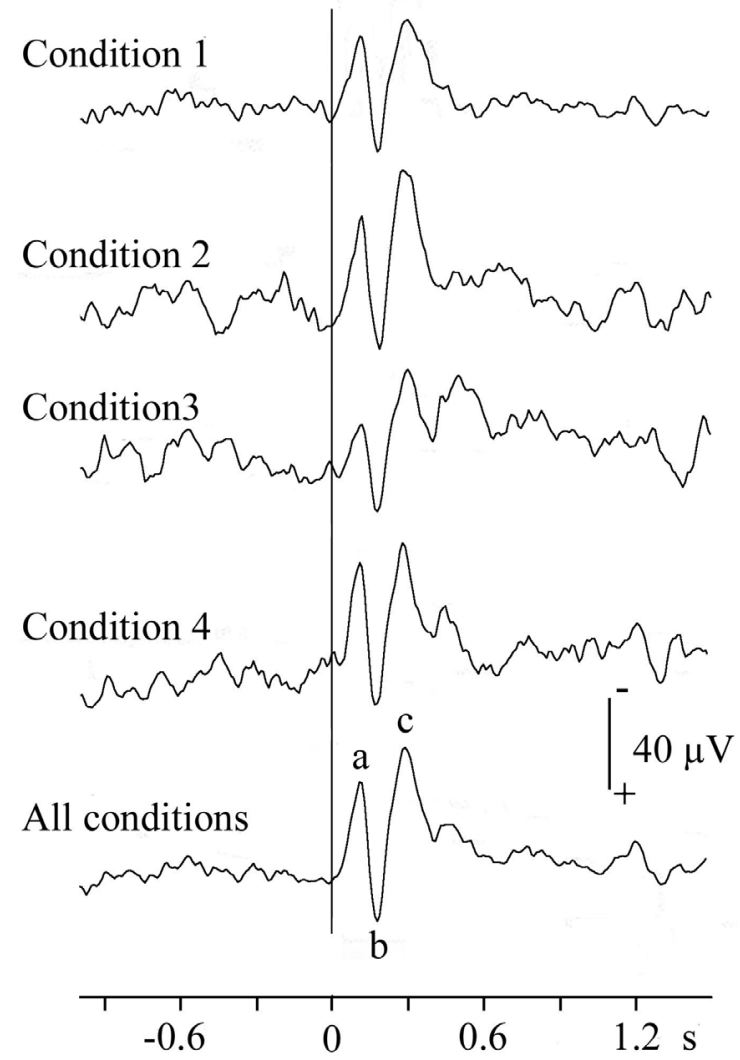

Fig. 1. One-condition and four-condition average responses calculated from records derived from the left cingulate gyrus in patient 9. The vertical line marks the onset of presentation of a warning auditory stimulus; the letters $a, b$, and $c$ on grand average designate prominent points of the frontal auditory evoked potential.

i) In the case of latencies of Point $a$, no significant difference between conditions $(\mathrm{F}(3,180)=0.1$; $\mathrm{p}>0.05$ values in post-hoc Scheffé test in all cases);

ii) In the case of latencies of Point $b$, no significant difference between conditions $(\mathrm{F}(3,180)=0.8$; $\mathrm{p}>0.05$ values in post-hoc Scheffé test in all cases);

iii) In the case of Point $a$-Point $b$ amplitude difference, no significant difference between conditions $(\mathrm{F}(3,180)=2.1 ; \mathrm{p}>0.05$ values in post-hoc Scheffé test in all cases).

As apparent, no influence of experimental conditions on FAEP parameters selected was demonstrated. This finding made it possible to continue analysis of early components of FAEP on averages calculated from data merged from all conditions. The more favorable signal-noise ratio of these grand averages allowed the estimation of onset time of the FAEPs and yielded the data for a more reliable analysis of the generation and build-up of their components.

\section{Origin and configuration of FAEP}

The configuration of FAEP was investigated on four-condition averages. In this analysis, only the curves from contacts located within or in the close vicinity of waveform generators were used. The generator was demonstrated on 20 electrodes of 10 patients. This demonstration was based either on the finding of a polarity reversal (4 cases) or a significant change of amplitude (16 cases; minimal change $16 \%$, maximal change $52 \%$, median $37 \%$ ) between two neighboring contacts of an electrode. Figure 2 shows representative waveforms from each of these 20 generators. There seems to be a common rule in the formation of a response: the first negative wave followed by the positive one and then, in almost all the cases, the second negative wave. With respect to the beginning of the stimulus, the mean latency of FAEP's onset was $52.8 \pm 16 \mathrm{~ms}$ (minimum $25 \mathrm{~ms}$, maximum 73 $\mathrm{ms}$ ), the mean latency of the first negative peak (Point $a$ ) 
Table 2. Brain localization and modality specificity of FAEP generators.

\begin{tabular}{|c|c|c|c|c|c|}
\hline $\begin{array}{l}\text { Generator } \\
\text { (Patient) }\end{array}$ & \multirow{2}{*}{$\begin{array}{l}\text { Brain localization, Broca's area, } \\
\text { hemisphere (right, left) }\end{array}$} & \multicolumn{3}{|c|}{$\begin{array}{l}\text { Talairach coordinates } \\
x, y, z\end{array}$} & \multirow{2}{*}{$\begin{array}{l}\begin{array}{l}\text { Response } \\
\text { specificity }\end{array} \\
\text { A }\end{array}$} \\
\hline (13) & & 53 & 3 & 17 & \\
\hline $2 \quad(5)$ & Cingulate gyrus, a32, L & -12 & 38 & 11 & $\mathrm{~A}+\mathrm{V}$ \\
\hline $3 \quad(6)$ & Cingulate gyrus, a32, $\mathrm{R}$ & 15 & 22 & 43 & $\mathrm{~A}+\mathrm{V}$ \\
\hline $4 \quad(7)$ & Cingulate gyrus, a32, $\mathrm{L}$ & -13 & 40 & 5 & A \\
\hline (9) & Cingulate gyrus, a32, $\mathrm{L}$ & -5 & 39 & 12 & $\mathrm{~A}$ \\
\hline $6 \quad(10)$ & Cingulate gyrus, $\mathrm{a} 32, \mathrm{R}$ & 5 & 33 & 16 & $A+V$ \\
\hline (4) & Precentral gyrus, a6, R & 55 & 0 & 35 & $\mathrm{~A}$ \\
\hline (8) & Precentral gyrus, a4, L & -43 & -12 & 40 & A \\
\hline $9 \quad(2)$ & Nucleus caudatus (caput), L & -10 & 15 & 3 & $A+V$ \\
\hline $10 \quad(1)$ & Inferior frontal gyrus (pars triangularis), a45, $\mathrm{R}$ & 55 & 34 & 6 & A \\
\hline 11 (8) & Precentral gyrus, a4, L & -9 & -20 & 50 & $\mathrm{~A}$ \\
\hline 12 (7) & Mediale frontal gyrus, a9, L & -30 & 43 & 30 & A \\
\hline 13 (7) & Mediale frontal gyrus, a46, L & -48 & 40 & 5 & A \\
\hline $14 \quad(9)$ & Mediale frontal gyrus, $\mathrm{a} 46, \mathrm{~L}$ & -50 & 39 & 12 & $\mathrm{~A}+\mathrm{V}$ \\
\hline $15 \quad(9)$ & Inferior frontal gyrus, a $47, \mathrm{~L}$ & -45 & 35 & -12 & $A+V$ \\
\hline $16 \quad(10)$ & Superior frontal gyrus, a11, R & 14 & 40 & -16 & $\mathrm{~A}+\mathrm{V}$ \\
\hline $17 \quad(13)$ & Inferior frontal gyrus (pars opercularis), a44, R & 55 & 10 & 28 & A \\
\hline 18 (1) & Precentral gyrus, a44, R & 52 & 7 & 15 & $\mathrm{~A}+\mathrm{V}$ \\
\hline $19 \quad$ (4) & Inferior frontal gyrus (pars opercularis), a44, $\mathrm{R}$ & 48 & 7 & 18 & A \\
\hline $20 \quad(7)$ & Superior frontal gyrus, a10, L & -18 & 35 & -12 & $\mathrm{~A}+\mathrm{V}$ \\
\hline
\end{tabular}

A - auditory responsiveness, $\mathrm{V}$ - visual responsiveness; generator numbers correspond to those given in Figure 2.

was $99.3 \pm 13 \mathrm{~ms}$ (minimum $67 \mathrm{~ms}$, maximum $115 \mathrm{~ms}$ ), the mean latency of the positive peak (Point $b$ ) was $180.8 \pm 28$ ms (minimum $128 \mathrm{~ms}$, maximum $258 \mathrm{~ms}$ ), and the mean latency of the second negative peak (Point $c$ ) was $324.1 \pm 63$ ms (minimum $214 \mathrm{~ms}$, maximum $446 \mathrm{~ms}$ ). The estimate of the onset time took into consideration the ongoing baseline oscillations which preceded the FAEP; in all the cases the onset value was located beyond their range. In all but case 11 , the polarity of individual components was identical. It is also evident that all the components exhibited a large variability of their values. The FAEP was extinguished mostly within $800 \mathrm{~ms}$. In a few cases, however, the negative shift of the baseline level at Point $c$ was maintained during the whole S1-S2 period (cases 14 and 17; see Figs 2 and 4). The data about the localization of these 20 FAEP generators are presented together with other relevant information in Table 2.

\section{FAEPs with very early onset}

The finding of FAEPs with very short onset latencies was another important result of the study. They were derived from three generators of three patients which were localized in the right gyrus precentralis. These FAEPs are presented in Figure 3 together with responses from neighboring electrode contacts. It is evident that in all three cases the waveforms with very short onset latency differed from the typical FAEP configuration; at the period which preceded the first negative wave, an additional sharp positive component appeared (see waveform R8 in case A (patient 13), R7 in case $\mathrm{B}$ (patient 1), and $\mathrm{R} 8$ in case $\mathrm{C}$ (patient 8); peak latency of $51 \mathrm{~ms}, 56 \mathrm{~ms}$, and $61 \mathrm{~ms}$, respectively). The onset of these FAEPs was estimated at $16 \mathrm{~ms}$ in all three cases.

\section{Modality specificity of FAEP generators}

The activity in all twenty generators during the presentation of the imperative visual stimulus was examined on average curves from Condition 1, where no action besides the mere observation of the screen was required. In eleven generators, no response to visual stimulus was observed (generators A). In the remaining nine cases (generators Av), the visual stimulus induced an evoked potential which started later with respect to the 

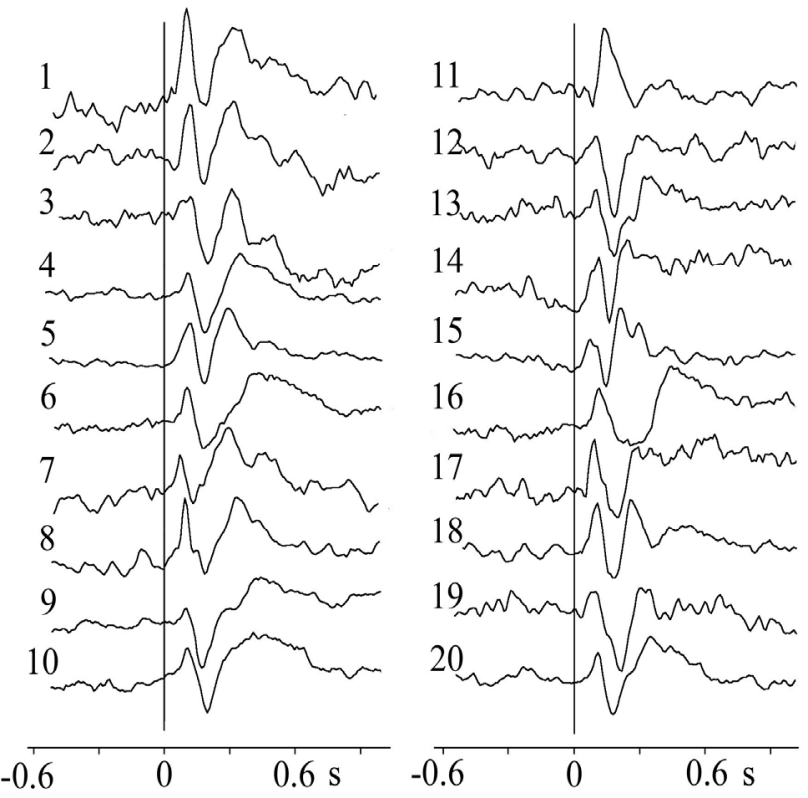

Fig. 2. Representative auditory evoked potentials derived from 20 generators. Four-condition averages are presented. The vertical line marks the onset of presentation of a warning auditory stimulus.

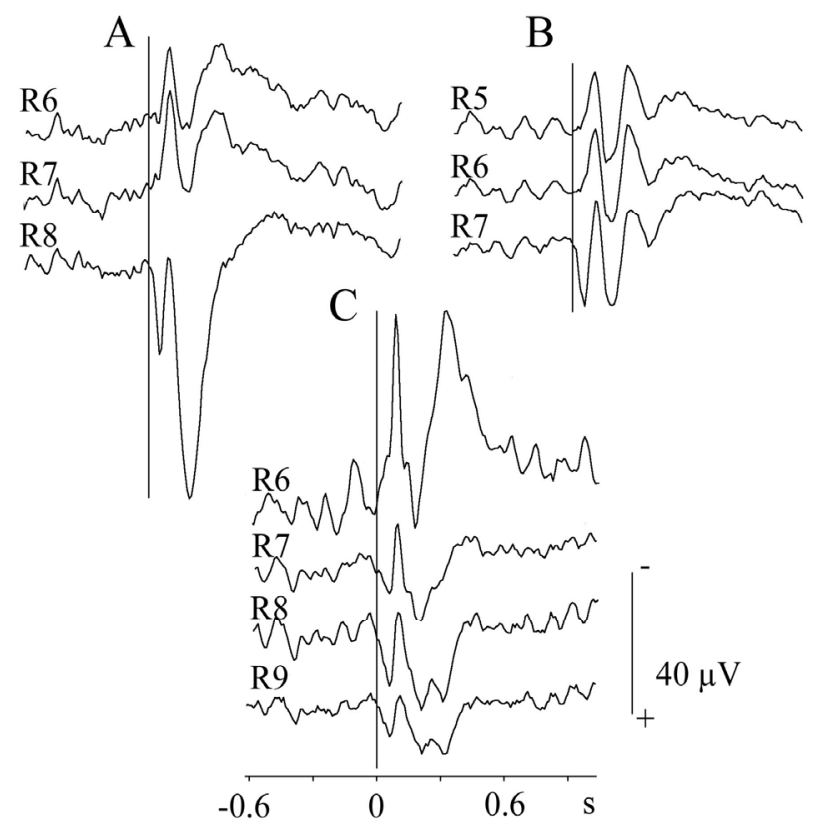

Fig. 3. Auditory evoked potentials with very early onsets (waveforms R8 in case A, R7 in case B, and R8 in case C) derived from three generators together with responses from neighboring contacts (four-condition averages are presented). The vertical line marks the onset of presentation of a warning auditory stimulus.

stimulus onset than the auditory response; the mean latency of Point $a$ of auditory response and of the corresponding point of the visual response was $107.0 \pm 19$ and $278.2 \pm 145$, respectively ( $<0.001$, Mann-Whitney $U$ test). Three selected curves from each subgroup are presented in Figure 4. A comparison of generators

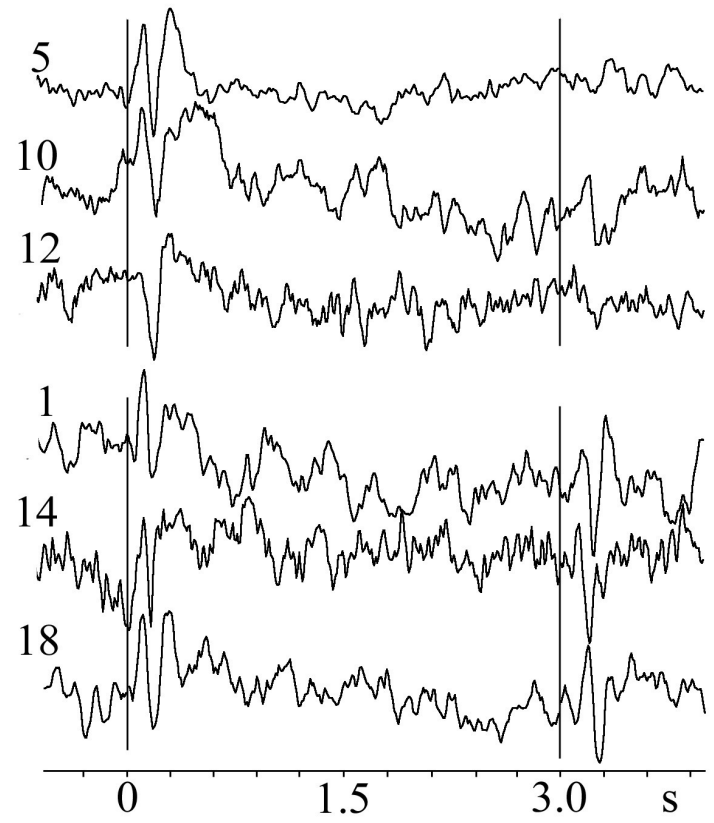

Fig. 4. Examples of evoked responses from generators with no response to visual stimulus (waveforms 5, 10, and 12) and generators with auditory and visual responsiveness (waveforms 1,14 , and 18). The numbers of waveforms correspond with the generator labels used in Table 2 . One-condition averages are presented. The vertical lines mark the onset of presentation of auditory or visual stimuli.

responding to one and two modalities showed a preferential localization of the first ones in motor cortices (6 generators A versus 1 generator Av). In a cingulate gyrus or frontal gyri the incidence of both types of generators was equal. The mean latency of Point $a$ was $95.4 \pm 12 \mathrm{~ms}$ in the case of generators A and $104.1 \pm 13 \mathrm{~ms}$ in the case of generators $A v(p=0.067$, Mann-Whitney $U$ test). The limited number of generators did not allow a more detailed analysis of differences between these two subgroups. In the case of FAEPs with very early onsets, no response to visual stimulus was observed in cases $\mathrm{A}$ and $\mathrm{C}$, and a clear-cut response with delayed onset was recorded in case $\mathrm{B}$.

\section{Discussion}

In interpreting data obtained by depth recordings in epileptic patients, their particular character must be taken into account. In fact, these data represent a by-product of the diagnostic procedure, which determined both the number and positioning of exploring electrodes. Therefore, the analyzed data can only give the information on brain areas which were limited in number and which were selected without regard to the function studied. Another limitation in interpreting the results stems from the fact that all the patients were under 
antiepileptic medication. Generally speaking, anticonvulsant drugs are used in the treatment of epilepsy for their potency to reduce the excitability of the structures involved in the seizures. The frequent side effects of these drugs comprising sedation, dizziness, attention, and cognitive and sensory disturbances suggest their more general influence on the brain function. As demonstrated by transcranial magnetic stimulation studies (Ziemann et al. 1996, Goyal et al. 2004), the alteration of the selected indicators of the brain activity varied greatly among the anticonvulsant drugs used. In our patients the doses of the drugs were, in accordance with the aim of the diagnostic procedure, reduced as much as possible. In fact, all the patients fulfilled the experimental tasks without any obvious sensory or behavioral deficit. The mean reaction time measured in condition 4 (attention visual-motor response) was $150 \pm 20 \mathrm{~ms}$, which did not prove any significant change with regard to the data from the literature concerning the performance of non-treated subjects.

The possible contribution of the intracerebrally recorded FAEPs to the scalp auditory evoked potential is the first question to be considered in evaluating the significance of the results obtained. The FAEPs from all 20 generators investigated in this study comprised a negative component with the mean peak latency at approximately $100 \mathrm{~ms}$. As the variability of these values was relatively small (in 17 cases these waves had their peaks within a narrow range of 90-115 ms) it is very probable that the component could represent the frontal contribution to the N1b wave of the scalp-recorded auditory evoked potentials.

Two other findings are relevant to the consideration of a possible functional significance of the FAEPs analyzed. The fact that some generator sites were activated while others did not change their activity in response to the visual stimulus is the first of these findings. The large variability of latency and configuration of FAEP component peaking at Point $c$ (latency of peaks from $214 \mathrm{~ms}$ to $446 \mathrm{~ms}$ ) was the second finding. The first result reflected differences in the ascendant pathways which conveyed the auditory stimuli to the frontal cortex, the second showed differences in underlying neuronal dynamics. Taken together, these differences demonstrated heterogeneity of FAEPs, which suggested their different functional role in auditory processing and related activities.

The demonstration that some frontal sites responded to both auditory and visual stimuli while other sites responded only to auditory stimuli, deserves a supplementary comment. The first type of these potentials seems to manifest an anatomical connection with non-specific subcortical areas from which the signals activated the recording sites. This connection could be either direct in the case of FAEPs with very early onset times or via an intermediate cortical source in the case of FAEPs with longer onset times. In interpreting their possible functional significance the following facts should be taken into account:

(i) The low cognitive and emotional demand of the situation (many times repeated presentation of the same stimulus in a situation which does not require any overt response);

(ii) The quasi simultaneous onset of modal nonspecific and modal specific activations (the difference between latencies of Point $a$ non-significant);

(iii) The presence of modal non-specific and modal specific activations in both recognition networks, i.e. in the "standard speed" and "fast speed" variants of the stimulus processing. These facts suggest the implication of a more general function, namely a form of the activation mechanism which generates specific neural states presented as a mandatory component of any activity or behavior (Danko 2008, Danko et al. 2008). From the available possibilities offered at present, the mechanism conceived as non-arousal, cognitive-specific attention activation best fits the presented facts.

The interpretation of the second type of FAEPs can be based on the description of steps supposed to underlie the completion of the task:

(i) Recognition of stimulus features;

(ii) Comparison of these features with the experimental instruction stored in the working memory;

(iii) Activation of mechanisms enabling the endogenous modulation of vigilant attention;

(iv) Increase of vigilant attention in expectation of the second, imperative stimulus.

In all of these operations the frontal lobes are known to play an important part. Thus it is not surprising to see modality-specific activation in frontal loci.

Another important result of the study was the finding of frontal auditory evoked potentials with very early onset in the precentral gyrus. Considering all the factors determining the propagation speed of the auditory stimulus from the loudspeaker to the frontal cortex, the FAEP onset at $16 \mathrm{~ms}$ seems to be correct providing that the signal was conveyed via the shortest possible pathway. Such characteristics together with the location 
of these potentials strongly suggest a relation to the developmental changes of auditory evoked potentials described by Bender et al. (2006). These authors hypothesized that the observed selective local agedependent maturation changes in the supplementary motor area could explain why adult subjects reacted substantially faster than children in the auditory simple reaction time tasks. In this context, the biological utility of a system, which enables response to a stimulus without amygdala evaluation of its significance, seems to be limited to situations with repeated, unchallenging stimuli. Otherwise, the risk of missing a potential threat signal could be too high. In any case, the finding of auditory evoked potentials with very early onset times in the frontal cortex could open up an interesting field for further research on fast response selection and performance in this kind of tasks.

In conclusion, a comparison of the prominent components of FAEPs revealed their variability, which suggested a different underlying neuronal dynamics and, very probably, a different functional significance. This information should be kept in mind especially when interpreting scalp-recorded auditory evoked potentials in clinical applications.

\section{Conflict of Interest}

There is no conflict of interest.

\section{Acknowledgements}

The authors thank for support by grants MSM 0021620849 and MSM 0021622404.

\section{References}

ALCAINI M, GIARD MH, THÉVENET M, PERNIER J: Two separate frontal components in the N1 wave of the human auditory evoked response. Psychophysiology 31: 611-615, 1994.

BAREŠ M, REKTOR I: Basal ganglia involvement in sensory and cognitive processing. A depth electrode CNV study in human subjects. Clin Neurophysiol 112: 2022-2030, 2001.

BENDER S, OELKERS-AX R, RESCH F, WEISBROD M: Frontal lobe involvement in the processing of meaningful auditory stimuli develops during childhood and adolescence. Neuroimage 33: 759-773, 2006.

CEPONIENE R, RINNE T, NÄÄTÄNEN R: Maturation of cortical sound processing as indexed by event-related potentials. Clin Neurophysiol 113: 870-882, 2002.

DANKO SG: Whole-cortex activations in mental functional states. Int J Psychophysiol 69: 151, 2008.

DANKO SG, BECHTEREVA NP, KACHALOVA LM, SOLOVJEVA ML: Cognitive-specific states of attention: EEG power correlates of memorization and retrieval. Int J Psychophysiol 69: 252-253, 2008.

FIETZEK UM, HEINEN F, BERWECK S, MAUTE S, HUFSCHMIDT A, SCHULTE-MONTING J, LUCKING CH, KORINTHENBERG R: Development of the corticospinal system and hand motor function: central conduction times and motor performance tests. Dev Med Child Neurol 42: 220-227, 2000.

GIARD MH, PERRIN F, ECHALLIER JF, THÉVENET M, FROMENT JC, PERNIER J: Dissociation of temporal and frontal components in the human auditory N1 wave: a scalp current density and dipole model analysis. Electroencephalogr Clin Neurophysiol 92: 238-252, 1994.

GOMES H, DUNN M, RITTER W, KURTHBERG D, BRATTSON A, KREUZER JA, VAUGHAN HG JR: Spatiotemporal maturation of the central and lateral N1 components to tones. Brain Res Dev Brain Res 129: 147-155, 2001.

GOODIN D, SQUIRES K, HENDERSON B, STARR A: Age-related variations in evoked potentials to auditory stimuli in normal human subjects. Electroencephalogr Clin Neurophysiol 44: 447-458, 1978.

GOYAL V, BHATIA M, BEHARI M: Increased depressant effect of phenytoin sodium as compared to carbamazepine on cortical excitability: a transcranial magnetic evaluation. Neurol India 52: 224-227, 2004.

HAMANO T, LUEDERS HO, IKEDAA, COLLURA TF, COMAIR YG, SHIBASAKI H: The cortical generators of the contingent negative variation in humans: a study with subdural electrodes. Electroencephalogr Clin Neurophysiol 104: 257-268, 1997.

HARI R, KAILA K, KATILA T, TUOMISTO T, VARPULA T: Inter-stimulus interval dependence of the auditory vertex response and its magnetic counterpart: implications for their neural generation. Electroencephalogr Clin Neurophysiol 54: 561-569, 1982. 
LAMARCHE M, LOUVEL J, BUSER P, REKTOR I: Intracerebral recordings of slow potentials in a contingent negative variation paradigm: an exploration in epileptic patients. Electroencephalogr Clin Neurophysiol 95 : 268-276, 1995.

NÄÄTÄNEN R, PICTON T: The N1 wave of the human electric and magnetic response to sound: a review and an analysis of the component structure. Psychophysiology 24: 375-425, 1987.

LIÉGEOIS-CHAUVEL C, MUSOLINO A, BADIER JM, MARQUIS P, CHAUVEL P: Evoked potentials from the auditory cortex in man: evaluation and topography of the middle latency components. Electroencephalogr Clin Neurophysiol 92: 204-214, 1994.

OPITZ B, RINNE T, MECKLINGER A, VON CRAMOND DY, SCHROEGER E: Differential contribution of frontal and temporal cortices to auditory change detection: fMRI and ERP results. Neuroimage 15: 167-174, 2002.

PANG EW, TAYLOR MJ: Tracking the development of the N1 from age 3 to adulthood: an examination of speech and non-speech stimuli. Clin Neurophysiol 111: 388-397, 2000.

PERRAULT N, PICTON T: Event-related potentials recorded from the scalp and nasopharynx. I. N1 and P2. Electroencephalogr Clin Neurophysiol 59: 177-194, 1984.

PONTON CW, EGGERMONT J, KWONG B, DON M: Maturation of human central auditory activity: evidence from multi-channel evoked potentials. Clin Neurophysiol 111: 220-236, 2000.

RINNE T, DEGERMAN A, ALHO K: Superior temporal and inferior frontal cortices are activated by infrequent sound duration decrements: an fMRI study. Neuroimage 26: 66-72, 2005.

TALAIRACH J, SZIKLA G: Atlas d'anatomie stéréotaxique du télencéphale. Masson, Paris, 1967.

TONNQUIST-UHLEN I, PONTON C, EGGERMONT J, KWONG B, DON M: Maturation of human cerebral auditory system activity: the T-complex. Clin Neurophysiol 114: 685-701, 2003.

TURAK B, LOUVEL J, BUSER P, LAMARCHE M: Event-related potentials recorded from the cingulated gyrus during attentional task: a study in patients with implanted electrodes. Neuropsychologia 40: 99-107, 2002.

WALTER GW, CROW HJ: Depth recording from the human brain. Electroencephalogr Clin Neurophysiol 16: 68-72, 1964.

ZIEMANN U, LONNECKER S, STEINHOFF BJ, PAULUS W: Effects of antiepileptic drugs on motor cortex excitability in humans: a transcranial magnetic stimulation study. Ann Neurol 40: 367-378, 1996. 